\title{
INVESTIGATION ON IMAGE PROCESSING PARAMETERS FOR PLATE EVALUATION IN TLC ANALYSIS OF MYCOTOXINS
}

\author{
DORINA CASONI ${ }^{a}$, MIHAELA BADEA ${ }^{\mathrm{b}}$, ILDIKO BROS ${ }^{\mathrm{c}}$, \\ SIMONA CODRUTA AURORA COBZAC ${ }^{\mathrm{a},{ }^{,}}$
}

\begin{abstract}
Based on advantages of available modern image processing techniques, thin-layer chromatography combined with image analysis becomes a promising alternative for the mycotoxins determinations in various foodstuffs. For this, the effect of digitizing channel selection and image processing parameters on aflatoxin B2 (AB2) and ochratoxin A (OTA) determination was evaluated and the obtained results were compared with those of classical photodensitometric analysis. The best exciting wavelength for OTA was found to be $\lambda_{\text {excitation }}=333 \mathrm{~nm}$ while for $\mathrm{AB} 2$ $\lambda_{\text {excitation }}=365 \mathrm{~nm}$. Low detection and quantification limits were determined ( $\mathrm{LOD}_{\text {OTA }}=0.310 \mathrm{ng} / \mathrm{spot} ; \quad \mathrm{LOQ}_{\text {OTA }}=0.616 \mathrm{ng} / \mathrm{spot}, \quad \mathrm{LOD}_{\mathrm{AB} 2}=0.557 \mathrm{ng} / \mathrm{spot}$, $\mathrm{LOQ}_{\mathrm{AB} 2}=1.098 \mathrm{ng} / \mathrm{spot}$ ). For image processing, the parameter with the highest influence upon the regression calibration curve was brightness and the best digitizing channel was found to be the green one. First-order calibration curve with a good determination coefficient $\left(R^{2}>0.99\right)$ were obtained on the working range of $2.5-50 \mathrm{ng} / \mathrm{spot}$. Although image processing techniques do not provide higher LOD and LOQ values than classical photodensitometry, this method offers the advantage of simultaneous quantification of both mycotoxins.
\end{abstract}

Keywords: aflatoxin B1, ochratoxin A, TLC; densitometry, image processing

\footnotetext{
${ }^{a}$ Babeş-Bolyai University, Faculty of Chemistry and Chemical Engineering, 11 Arany Janos Street, Cluj-Napoca, Romania

${ }^{b}$ Transilvania University of Brasov, Faculty of Medicine, 56 N. Balcescu. Street, Brasov, Romania

${ }^{c}$ National Institute for Research and Development of Isotopic and Molecular Technologies, 65-103 Donath Street, Cluj-Napoca, Romania

*Corresponding author: csimona@chem.ubbcluj.ro
} 


\section{INTRODUCTION}

Mycotoxins are toxic secondary metabolite produced by moulds. One mould species can produce many different mycotoxins, and the same mycotoxin can be produced by several species. Mycotoxins may appear in the food chain as a result of fungal infection or improper storage conditions. Some mycotoxins are mutagenic and carcinogenic while other present specific organ toxicity. Mycotoxins are resistant against chemical decomposition, digestion or temperature treatments, such as cooking and freezing. The scientific literature offers a wide range of information on the occurrence of mycotoxins in food and feed [1,2]. Due to their toxicity, aflatoxins and ochratoxins are the most studied mycotoxins.

Aflatoxins are produced by the Aspergillus species of fungi. The main source of mycotoxins is Aspergillus flavus that has in its composition four toxic compounds known as - aflatoxin B1, B2, G1 and G2. When aflatoxins B1 and B2 are ingested by lactating cows, a small proportion is converted to hydroxylated compounds (aflatoxins M1 and M2) which are excreted in milk. Structurally, aflatoxins are highly substituted coumarins (Fig.1). Under UV light, aflatoxins B present blue fluorescence, aflatoxins G present green fluorescence and aflatoxins $M$ present violet fluorescence. Aflatoxins have teratogenic effects and can induce acute liver damage, liver cirrhosis and tumors development. Their toxicity decreases as follows: B1; $\mathrm{M} 1 ; \mathrm{G} 1 ; \mathrm{B} 2 ; \mathrm{M} 2$ and $\mathrm{G} 2$ [3].
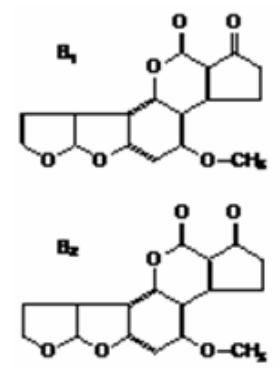
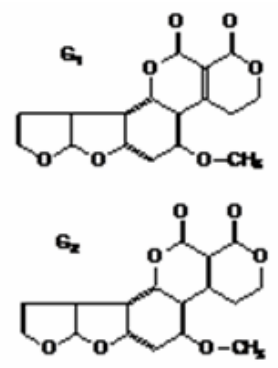
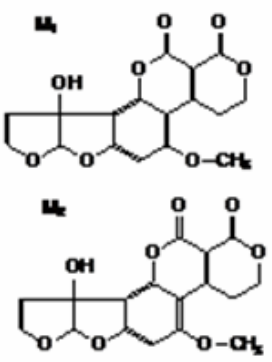

Figure 1. Aflatoxins structures

Ochratoxins are produced by Aspergillus and Penicilium species. There are at least seven structurally related compounds from which ochratoxins A (OTA), B (OTB) and C (OTC) are the most known (Fig.2). Like most other mycotoxins they are stable at high temperatures and under UV light present green (OTA) or blue fluorescence. OTA is more toxic than 
OTB and OTC. Ochratoxins have immunotoxic, teratogenic and carcinogenic effects [4]. Human chronic OTA exposure is linked to increased incidences of nephropathy and urothelial tumors, especially in the Balkan region.
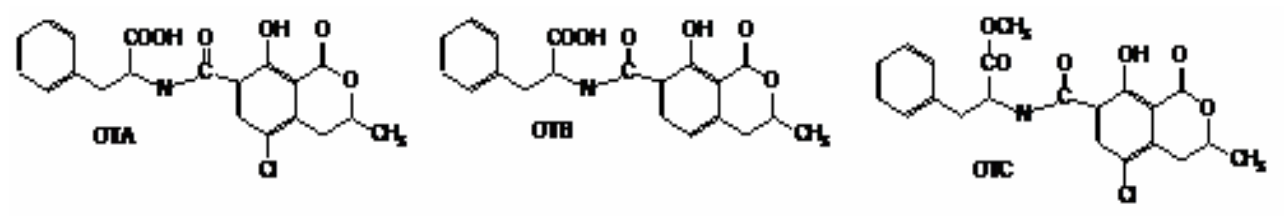

Figure 2. Ochratoxins structure

Grains, dried beans (cocoa, coffee and soy beans), barley, citrus, their products and wine can be contaminated when improper storage conditions are used. Ochratoxins can also be accumulated in meat and meat products.

Taking into account their high toxicity, regulatory limits have been established in many countries worldwide. The Commission of the European Communities [5] has set the maximum admitted levels for mycotoxins at $\mu \mathrm{g} / \mathrm{kg}$ in different foods.

From the viewpoint of the food production industry, raw materials should be analyzed to screen the presence of mycotoxins using fast techniques such as enzyme-linked immunosorbent assay (ELISA) or electrochemical methods using biosensor. Confirmatory methods relay on chromatographic techniques such as high performance liquid chromatography (HPLC), thin layer chromatography (TLC), gas chromatography (CG) and capillary electrophoresis (CE) [6]. Scientific literature presents many review articles regarding mycotoxins analysis [7-10]. By far, the most commonly used technique is RP-HPLC. Isocratic [9] as well gradient elution with organic solvent (methanol, acetonitril) and aqueous solution can be used $[12,13]$. Detection is achieved by fluorimetric measurements [12] or by coupling with a mass spectrometer $[15,16]$.

TLC analysis for mycotoxins is still popular for both qualitative and quantitative determinations [17-24]. Silica gel layers seem to be the most common stationary phases used for such investigations. Different mobile phases combined with single, multiple, mono-dimensional or bidimensional development procedures $[19,23]$ were employed depending on the mycotoxins polarity and matrix complexity. Plate documentation was achieved either by measuring the fluorescence emission after UV light $(364 \mathrm{~nm})$ exposure or after spraying the plate with different reagents. Both scanning densitometry and image analysis techniques 
were employed for spot area evaluation. While linear calibration curve is preferred in quantitative analyses, second-order polynomial dependence between spots area and concentration was often observed in the case of image processing techniques.

In the matter of TLC combined with image analysis method, even for linear signal/concentration dependence, the accuracy in spot area determination can be strongly influenced by variation of image processing parameters (as contrast and brightness) usually involved in such methodology. Moreover, the quantification of mycotoxins by TLC leads to an increased difficulty due to their native fluorescence property.

Taking into account the importance of detection and quantification of mycotoxins in various foodstuffs, the purpose of this study is to evaluate the effect of different image processing parameters on the thin-layer chromatographic determination of mycotoxins. For this, the effect of color channel, contrast and brightness selection on the mycotoxins (OTA, AB2) quantification will be evaluated based on linear dependence parameters (slope and coefficient of determination $\left(R^{2}\right)$ ) and method performance capacity (limit of detection (LOD) and limit of quantification (LOQ)).

\section{RESULTS AND DISCUSSION}

TLC analysis was carried out on Silica gel HPTLC plates using different solvent mixtures (Table 1) as mobile phase, the most efficient separation being achieved with ethyl acetate - toluene - formic acid $(30: 1.5: 1, v / v)$. The chromatogram obtained in the conditions mentioned above is presented in Figure 3.

Table 1. Mobile phases used for OTA and AB2 separation on Silica gel plates

\begin{tabular}{|c|c|c|c|}
\hline \multirow{2}{*}{$\begin{array}{l}\mathrm{Nr} . \\
\text { crt. }\end{array}$} & \multirow[t]{2}{*}{ Mobile phase } & \multicolumn{2}{|c|}{$R_{f}$ value } \\
\hline & & OTA & AB2 \\
\hline 1 & Toluene - Methanol - Acetic acid (6:3:1, v/v) & 0.78 & 0.79 \\
\hline 2 & Ethyl acetate - Toluene - Formic acid $-\mathrm{H}_{2} \mathrm{O}(30: 1.5: 4: 3, \mathrm{v} / \mathrm{v})$ & 0.96 & 0.74 \\
\hline 3 & Ethyl acetate - Toluene - Formic acid $-\mathrm{H}_{2} \mathrm{O}(30: 1.5: 2: 1.5, \mathrm{v} / \mathrm{v})$ & 0.94 & 0.56 \\
\hline 4 & $\begin{array}{l}\text { Ethyl acetate - Toluene - Formic acid } \\
\qquad(30: 1.5: 1, \mathrm{v} / \mathrm{v})\end{array}$ & 0.78 & 0.30 \\
\hline 5 & $\begin{array}{c}\text { Ethyl acetate - Toluene - Formic acid } \\
\qquad(30: 2.5: 0.5, \mathrm{v} / \mathrm{v})\end{array}$ & 0.68 & 0.25 \\
\hline
\end{tabular}




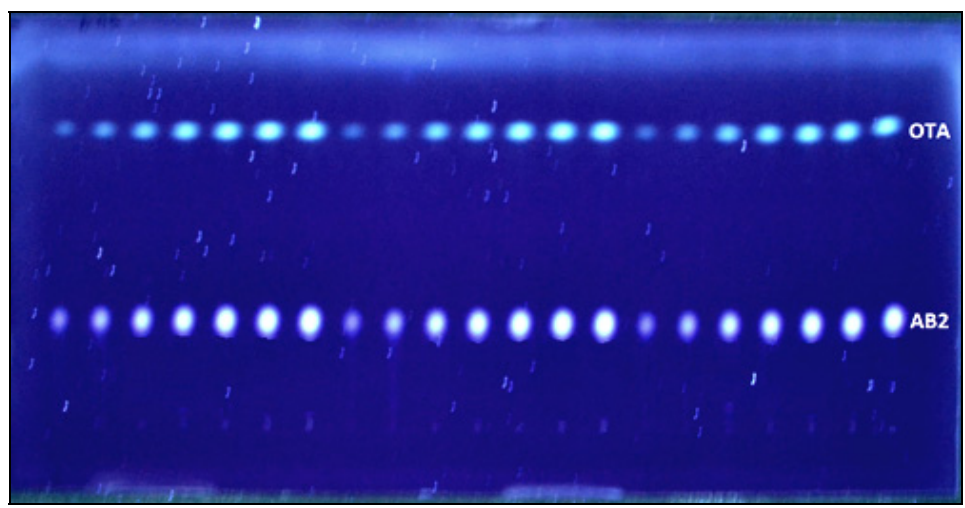

Figure 3. The chromatogram of separated mycotoxins using Silica gel HPTLC plates, mobile phase ethyl acetate - toluene - formic acid $(30: 1.5: 1, \mathrm{v} / \mathrm{v})$ and fluorescence mode $\left(\lambda_{\text {excitation }}=365 \mathrm{~nm}\right)$

For the determination of calibration curve equation, the plate was evaluated both by photodensitometry and by image processing. Photodensitometric measurements were carried out using two exciting wavelengths $-365 \mathrm{~nm}$ and $333 \mathrm{~nm}$ (Figure 4).

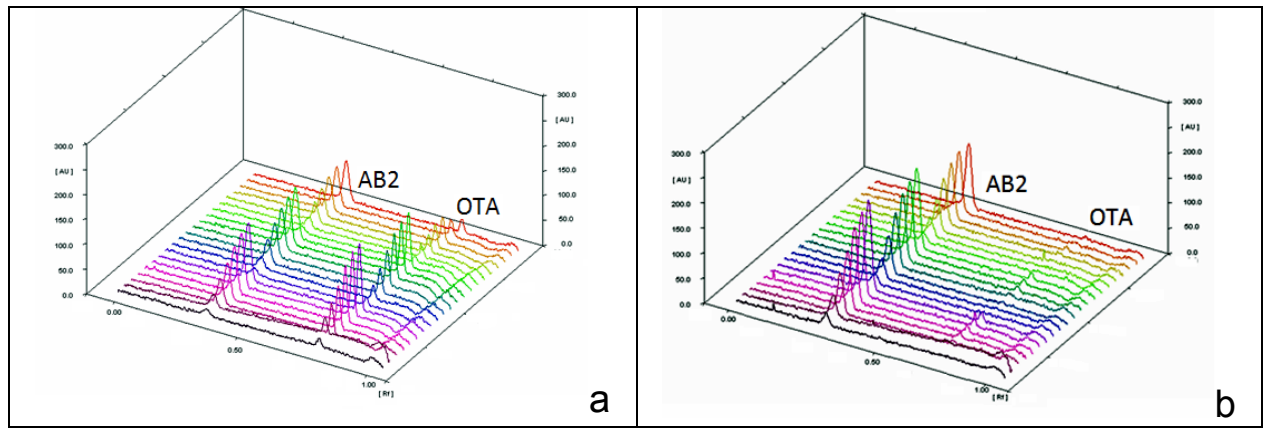

Figure 4. OTA and $A B 2$ digitized chromatograms obtained using densitometric investigations at (a) $\lambda_{\text {excitation }}=333 \mathrm{~nm}$ and (b) $\lambda_{\text {excitation }}=365 \mathrm{~nm}$

By plotting the emission signal vs. mycotoxins concentration (ng/spot), linear calibration curves were obtained in the working range of concentration 2.50 - 50ng/spot (Table 2). It has been noticed that incident radiation influences the size of the emission signal so that OTA can be determined only for $\lambda_{\text {excitation }}=365 \mathrm{~nm}$. Moreover, AB2 can be determined at both wavelengths. Contrarily to OTA determination, the excitation radiation of $365 \mathrm{~nm}$ offers the highest sensitivity for AB2 with show the lowest value of detection limit (LOD) in these conditions (Table 2). 
Table 2. Calibration parameters for OTA and AB2 obtained based on densitometric evaluation of HPTLC plates

\begin{tabular}{|c|c|c|c|c|c|c|}
\hline \multirow[t]{2}{*}{ Compound } & \multirow{2}{*}{$\begin{array}{l}\text { Aexcitation } \\
(\mathrm{nm})\end{array}$} & \multicolumn{3}{|c|}{ Linear regression parameters } & \multirow{2}{*}{$\begin{array}{l}\text { LOD } \\
\text { (ng) }\end{array}$} & \multirow{2}{*}{$\begin{array}{c}\text { LOQ } \\
\text { (ng) }\end{array}$} \\
\hline & & Slope & Intercept & $\mathrm{R}^{2}$ & & \\
\hline \multirow[t]{2}{*}{ OTA } & 333 & 88.764 & 268.19 & 0.9975 & 0.310 & 0.616 \\
\hline & 365 & --- & --- & --- & --- & -- \\
\hline \multirow[t]{2}{*}{ AB2 } & 333 & 118.04 & 205.83 & 0.9991 & 0.951 & 1.854 \\
\hline & 365 & 171.62 & 248.78 & 0.9997 & 0.557 & 1.098 \\
\hline
\end{tabular}

So far, image processing in TLC analysis has no established predefined rules. In principle, it is beneficial to use those combinations of processing parameters (contrast/brightness) that provide a white background, but do not lead to great loss of information. Moreover, when fluorescence visualization mode is used, an inversion operation is necessary in order to obtain positive values for spot area determination. Usually this procedure leads especially to background alteration and increases the difficulty of choosing the processing parameters. To have a deep insight of the problem, the image analysis was firstly performed without changing the contrast and brightness parameters. In this case a second-order calibration curve (spot area/concentration) was obtained for both investigated mycotoxins. Furthermore, if a linear dependence was taken into consideration, a significant decrease of the determination coefficient $\left(R^{2}\right)$ was observed (Table 3$)$.

Table 3. Calibration curve equations for OTA and $A B 2$ mycotoxins obtained by selecting different colour channels (grey (GY), green (GR) and blue (BL)) and without altering the contrast and brightness parameters

\begin{tabular}{|c|c|c|c|c|}
\hline \multirow{2}{*}{ 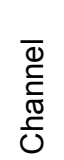 } & \multicolumn{4}{|c|}{ OTA calibration curve equation } \\
\hline & $Y=a x^{2}+b x+c$ & $\mathrm{R}^{2}$ & $Y=a x+b$ & $\mathrm{R}^{2}$ \\
\hline GY & $Y=-118.92 x^{2}+17717 x+84103$ & 0.9935 & $Y=11219 x+142585$ & 0.9752 \\
\hline GR & $Y=-209.85 x^{2}+27300 x+129347$ & 0.9945 & $Y=15832 x+232562$ & 0.9661 \\
\hline \multirow[t]{2}{*}{$\mathrm{BL}$} & $Y=-285.16 x^{2}+14590 x+382774$ & 0.9968 & $Y=19358 x+361196$ & 0.9847 \\
\hline & \multicolumn{4}{|c|}{ AB2 calibration curve equation } \\
\hline GY & $Y=-318.15 x^{2}+30849 x+261575$ & 0.9794 & $Y=8654.9 x+472759$ & 0.6717 \\
\hline GR & $Y=-383.39 x^{2}+40284 x+216681$ & 0.9861 & $Y=13539 x+471167$ & 0.7733 \\
\hline $\mathrm{BL}$ & $Y=-398.96 x^{2}+39536 x+186287$ & 0.9880 & $Y=11709 x+451072$ & 0.7092 \\
\hline
\end{tabular}




\section{INVESTIGATION ON IMAGE PROCESSING PARAMETERS FOR PLATE EVALUATION ...}

By increasing the contrast and brightness with different percentages values the linear spot area/concentration dependence was observed. The calibration curve parameters and performance of detection and quantification obtained for different values of contrast $(\mathrm{C} 1-\mathrm{C} 3)$ and brightness (B2-B4) are presented in Table 4.

The graphical representation of the slope according to the image processing parameters for each of the channel selected for chromatogram digitization highlights several aspects, namely: (i) the highest values of the slope are obtained for the grey and green channels; (ii) high slope values are obtained for low brightness selection (B2); (iii) the slope values decrease as the brightness increases (B3, B4); (iv) for the same brightness value, an increased contrast results in a slightly increased slope. To exemplify, only OTA graphical representation (Figure 5 ) is presented, but a similar trend has also been observed for AB2.

Table 4. Calibration parameters obtained by image processing at different contrast and brightness values on grey (GY), green (GR) and blue (BL) evaluation channels

\begin{tabular}{|c|c|c|c|c|c|c|c|}
\hline \multirow[b]{2}{*}{ 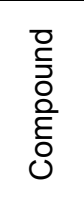 } & \multirow[b]{2}{*}{ 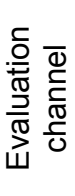 } & \multirow{2}{*}{$\begin{array}{c}\text { Image } \\
\text { processing } \\
\text { parameters } \\
\text { (contrast, } \\
\text { brightness) }\end{array}$} & \multicolumn{3}{|c|}{ Linear regression parameters } & \multirow[b]{2}{*}{ 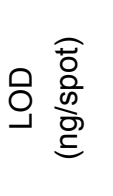 } & \multirow[b]{2}{*}{ 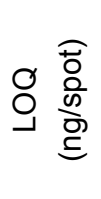 } \\
\hline & & & Slope & Intercept & $\mathrm{R}^{2}$ & & \\
\hline \multirow{15}{*}{ OTA } & \multirow{9}{*}{ GY } & C1B2 & 1026.6 & 29657 & 0.9928 & 3.318 & 6.322 \\
\hline & & C1B3 & 983.2 & 21829 & 0.9948 & 2.814 & 5.403 \\
\hline & & C1B4 & 893.8 & 17489 & 0.9922 & 3.452 & 6.566 \\
\hline & & $\mathrm{C} 2 \mathrm{~B} 2$ & 1096.4 & 28280 & 0.9945 & 2.894 & 5.549 \\
\hline & & C2B3 & 1014.2 & 23077 & 0.9936 & 3.143 & 6.005 \\
\hline & & C2B4 & 938.5 & 18968 & 0.9912 & 3.681 & 6.977 \\
\hline & & C3B2 & 1091.6 & 28769 & 0.9942 & 2.971 & 5.691 \\
\hline & & C3B3 & 1041.2 & 24648 & 0.9924 & 3.422 & 6.511 \\
\hline & & C3B3 & 1003.0 & 20495 & 0.9913 & 3.649 & 6.920 \\
\hline & \multirow{6}{*}{ GR } & C1B2 & 1520.6 & 29242 & 0.9940 & 3.038 & 5.814 \\
\hline & & C1B3 & 1425.0 & 19666 & 0.9938 & 3.082 & 5.894 \\
\hline & & C1B4 & 1358.2 & 12964 & 0.9910 & 3.721 & 7.048 \\
\hline & & $\mathrm{C} 2 \mathrm{~B} 2$ & 1570.4 & 28420 & 0.9917 & 3.571 & 6.779 \\
\hline & & C2B3 & 1514.3 & 20432 & 0.9912 & 3.679 & 6.974 \\
\hline & & C2B4 & 1444.2 & 14359 & 0.9908 & 3.758 & 7.115 \\
\hline
\end{tabular}


D. CASONI, M. BADEA, I. BROS, S. C. A. COBZAC

\begin{tabular}{|c|c|c|c|c|c|c|c|}
\hline \multirow{14}{*}{ 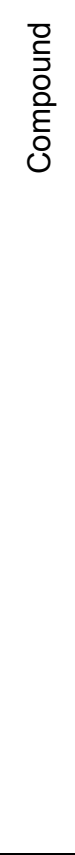 } & \multirow{5}{*}{ 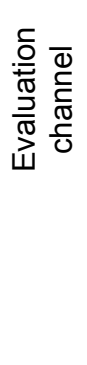 } & & \multicolumn{3}{|c|}{ Linear regression parameters } & \multirow[b]{2}{*}{ 오 } & \multirow[b]{2}{*}{ 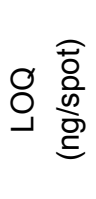 } \\
\hline & & $\begin{array}{c}\text { processing } \\
\text { parameters } \\
\text { (contrast, } \\
\text { brightness) }\end{array}$ & Slope & Intercept & $\mathrm{R}^{2}$ & & \\
\hline & & C3B2 & 1586.9 & 28272 & 0.9901 & 3.895 & 7.359 \\
\hline & & C3B3 & 1577.9 & 21798 & 0.9895 & 4.027 & 7.594 \\
\hline & & C3B3 & 1543.4 & 16225 & 0.9896 & 3.999 & 7.543 \\
\hline & \multirow{9}{*}{$B L$} & C1B2 & 1562.5 & 67058 & 0.9792 & 5.688 & 10.46 \\
\hline & & C1B3 & 1486.2 & 49282 & 0.9915 & 3.613 & 6.854 \\
\hline & & C1B4 & 1342.5 & 41267 & 0.9888 & 4.151 & 7.812 \\
\hline & & $\mathrm{C} 2 \mathrm{~B} 2$ & 1611.8 & 62241 & 0.9894 & 4.032 & 7.602 \\
\hline & & C2B3 & 1539.6 & 50885 & 0.9923 & 3.435 & 6.534 \\
\hline & & C2B4 & 1412.5 & 43639 & 0.9905 & 3.829 & 7.241 \\
\hline & & C3B2 & 1660.4 & 61335 & 0.9932 & 3.225 & 6.153 \\
\hline & & C3B3 & 1574.5 & 53787 & 0.9916 & 3.588 & 6.810 \\
\hline & & C3B3 & 1503.0 & 46513 & 0.9916 & 3.588 & 6.811 \\
\hline \multirow{17}{*}{ AB2 } & \multirow{9}{*}{ GY } & C1B2 & 1722.3 & 60569 & 0.9944 & 2.930 & 5.615 \\
\hline & & C1B3 & 1602.5 & 49886 & 0.9964 & 2.342 & 4.527 \\
\hline & & C1B4 & 1509.1 & 41833 & 0.9933 & 3.194 & 6.097 \\
\hline & & C2B2 & 1880.8 & 58338 & 0.9902 & 3.889 & 7.347 \\
\hline & & C2B3 & 1741.7 & 50919 & 0.9889 & 4.145 & 7.801 \\
\hline & & C2B4 & 1615.5 & 44102 & 0.9964 & 2.338 & 4.521 \\
\hline & & C3B2 & 1848.4 & 60266 & 0.9955 & 2.631 & 5.065 \\
\hline & & C3B3 & 1786.0 & 53911 & 0.9966 & 2.263 & 4.381 \\
\hline & & C3B3 & 1734.5 & 47183 & 0.9966 & 2.280 & 4.412 \\
\hline & \multirow{8}{*}{ GR } & C1B2 & 2497.8 & 24195 & 0.9933 & 3.203 & 6.113 \\
\hline & & C1B3 & 2476.4 & 10208 & 0.9953 & 2.671 & 5.139 \\
\hline & & C1B4 & 2401.2 & 15640 & 0.9918 & 3.555 & 6.751 \\
\hline & & C2B2 & 2671.4 & 21222 & 0.9981 & 1.717 & 3.350 \\
\hline & & C2B3 & 2577.9 & 12436 & 0.9974 & 1.992 & 3.872 \\
\hline & & C2B4 & 2465.8 & 52389 & 0.9961 & 2.433 & 4.698 \\
\hline & & C3B2 & 2656.5 & 23156 & 0.9977 & 1.879 & 3.656 \\
\hline & & C3B3 & 2653.7 & 14404 & 0.9972 & 2.057 & 3.993 \\
\hline
\end{tabular}


INVESTIGATION ON IMAGE PROCESSING PARAMETERS FOR PLATE EVALUATION ...

\begin{tabular}{|c|c|c|c|c|c|c|c|}
\hline \multirow{12}{*}{ 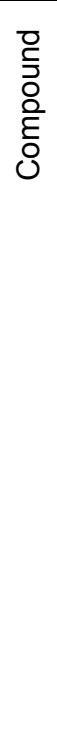 } & \multirow{3}{*}{ 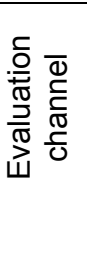 } & \multirow{2}{*}{$\begin{array}{c}\text { Image } \\
\text { processing } \\
\text { parameters } \\
\text { (contrast, } \\
\text { brightness) }\end{array}$} & \multicolumn{3}{|c|}{ Linear regression parameters } & \multirow[b]{2}{*}{ 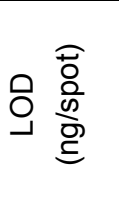 } & \multirow[b]{2}{*}{ 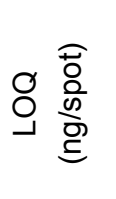 } \\
\hline & & & Slope & Intercept & $\mathrm{R}^{2}$ & & \\
\hline & & C3B3 & 2688.2 & 49674 & 0.9981 & 1.693 & 3.040 \\
\hline & \multirow{9}{*}{$\mathrm{BL}$} & C1B2 & 2745.2 & 158106 & 0.9955 & 2.613 & 5.032 \\
\hline & & C1B3 & 2596.8 & 135920 & 0.9842 & 4.948 & 9.201 \\
\hline & & C1B4 & 2313.1 & 122101 & 0.9806 & 5.493 & 10.130 \\
\hline & & C2B2 & 2915.3 & 159552 & 0.9966 & 2.293 & 4.437 \\
\hline & & C2B3 & 2667.8 & 143588 & 0.9951 & 2.777 & 5.335 \\
\hline & & C2B4 & 2419.3 & 130082 & 0.9956 & 2.593 & 4.994 \\
\hline & & C3B2 & 2936.7 & 161544 & 0.9922 & 3.465 & 6.589 \\
\hline & & C3B3 & 2847.9 & 148667 & 0.9865 & 4.570 & 8.546 \\
\hline & & C3B3 & 2644.3 & 137618 & 0.9950 & 2.765 & 5.313 \\
\hline
\end{tabular}

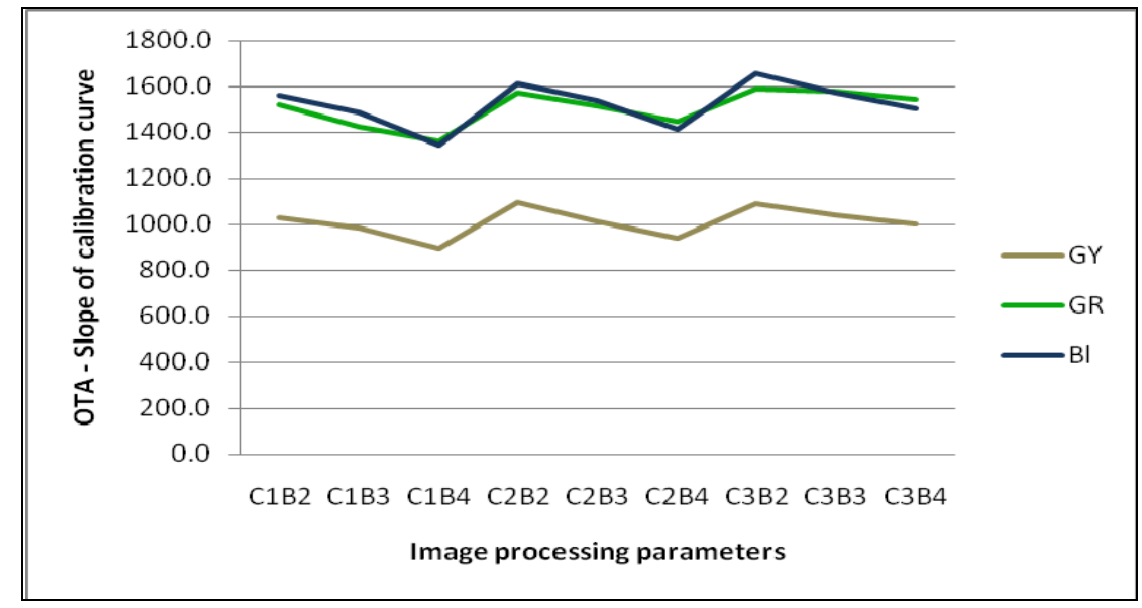

Figure 5. Slope variation according to image processing parameters (contrast (C1C3) and brightness (B2-B4)) and selection of different colour channels (grey (GY), green (GR) and blue (BL)) for chromatogram digitization

For OTA, the determination coefficients $\left(R^{2}\right)$ ranged from 0.9948 (GY) to $0.9901(\mathrm{BL})$. The performance parameters LOD and LOQ show a variation in the range $2.814(\mathrm{GY})-4.151(\mathrm{BL}) \mathrm{ng} / \mathrm{spot}$ respectively 5.403 $(\mathrm{GY})$ - $7.812(\mathrm{BL}) \mathrm{ng} / \mathrm{spot}$. For $\mathrm{AB} 2$ quantification, the higher determination 
coefficient $\left(R^{2}=0.9981\right)$ and the lower value for detection and quantification ( $L O D=1.693 \mathrm{ng} / \mathrm{spot}, \mathrm{LOQ}=3.040 \mathrm{ng} / \mathrm{spot}$ ) were obtained by selecting the green channel for chromatograms evaluation.

The principal component analysis technique (PCA) was applied on data matrices consisting in numerical values of the slope, intercept and determination coefficient (as independent variables) corresponding to the investigated processing parameters (contrast (C1-C3) and brightness (B2B4)) and colour channels (grey (GY), green (GR) and blue (BL)) used for chromatograms digitization. Based on the PCA investigations of OTA matrix, the most significant results are discussed as follows. The first principal component (PC1, representing $58 \%$ of the total variance in the data set) contains $34 \%$ information data regarding the slope, 39\% regarding the intercept and $27 \%$ regarding the determination coefficient. The second PC (PC2, accounting $28 \%$ from the data variability) contains $67 \%$ information data regarding determination coefficient and $30 \%$ regarding the slope. The third PC (PC3, accounting $17.33 \%$ of data variability) is associated in a proportion of $58 \%$ to the intercept. The graphical representation of the PC3 vs. PC1 (Figure 6) shows that green channel (GR) selection for plate evaluation leads to a significant difference in method sensitivity (significantly higher values of PC3) compared to the grey (GY) and blue (BL) channels (that show no significant differences in PC3 values).

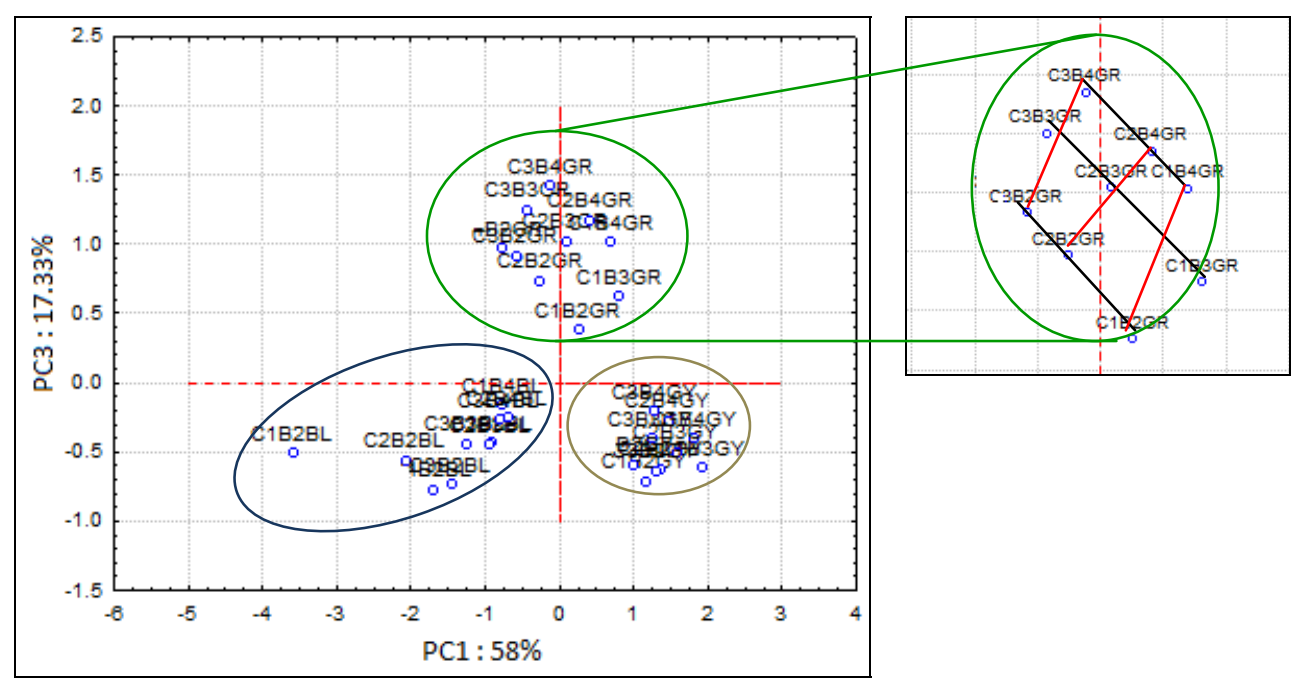

Figure 6. Projection of the cases (contrast, brightness, and digitizing channel) on the factor-plane (PC1 vs. PC3) obtained by PCA analysis on OTA regression parameters matrix 
Moreover, for the green (GR) channel, it was observed a direct dependence of regression parameters (slope, intercept and determination coefficient) with brightness (black lines) and an inverse with contrast (red line) when processing parameters were increased with constant increments. The same behaviour was also observed in the case of AB2 investigations, but the direct relationships on the regression parameters based on the same brightness or contrast variations were not so evident.

\section{CONCLUSIONS}

The fluorescence photodensitometric investigation shows that both mycotoxins ( $A B 2$ and OTA) can be determined using $333 \mathrm{~nm}$ as excitation wavelength, while $365 \mathrm{~nm}$ leads to an increased sensitivity for $A B 2$ determination. Moreover, better values for determination coefficient $\left(R^{2}\right)$, and method performance parameters (LOD and LOQ) were obtained, compared to published data in scientific literature [24].

The image processing investigation revealed several aspects, namely: (i) linear calibration curve can be obtained by a proper image processing; (ii) the best digitizing channel for fluorescence evaluation mode is the green one; (iii) high slope values are obtained for low brightness selection; (iv) the slope values decrease as the brightness increases; $(\mathrm{v})$ an increased contrast results in a slight slope increase; (vi) LOD and LOQ values obtained by image processing are comparable to those obtained by photodensitometric method.

Taking into account the above presented issues, it has been concluded that, besides the classical photodensitometric TLC evaluation technique, the modern technique of image processing can also be used with good results for mycotoxins analysis.

\section{EXPERIMENTAL SECTION}

\section{Reagents and materials}

Aflatoxin B2 (AB2) and ochratoxin A (OTA) were obtained from Fluka (Switzerland). Ethyl acetate, toluene and formic acid were from the Chemical Company (lași, România). HPTLC Silica gel 60 plates $(20 \mathrm{~cm} \times 10$ $\mathrm{cm}$ ) were acquired from Merck (Germany). Standard solution of OTA $(2.5 \mu \mathrm{g} / \mathrm{mL})$ and AB2 $(2.5 \mu \mathrm{g} / \mathrm{mL})$ was prepared in methanol.

\section{Analytical equipment and Software}

Linomat 5 TLC applicator (CAMAG, Muttenz, Switzerland) with an application rate of $80 \mathrm{~nL} \mathrm{~s}{ }^{-1}$ was used for standards application. A Nikon 
CCD camera was used to capture the image of chromatographic plates and Camag TLC Scanner 3 (Camag, Switzerland) for densitometric evaluation of the chromatographic plates. ImageDecipher-TLC software version 2.0 (BioDit Technology, Co. www.biodit.com) was used for the digital processing of images and spot area integration. Limits of detection and quantification (LOD and LOQ) were calculated using statistical methods in analytical chemistry (SMAC) (Meier, 1993). Statistica 8.0 software package (www.statsoft.org) was used for statistical data treatment.

\section{Thin Layer Chromatographic Analysis}

The separation of the investigated mycotoxins was performed on high-performance silica gel 60 plates $(20 \mathrm{~cm} \times 10 \mathrm{~cm}$, Merck, Darmstadt, Germany). Spots of $1-20 \mu \mathrm{L}$ of standard solutions were applied at $15 \mathrm{~mm}$ distance from the edges of plate. The plates were developed in a saturated chamber using different mixtures of solvents as the mobile phase. The evaluation of the plate was performed using the classical photodensitometry and modern image analysis technique respectively. Two excitation wavelengths, $365 \mathrm{~nm}$ and $333 \mathrm{~nm}$, were used for fluorescence photodensitometry. The modern assessment technique involves digitizing of the chromatographic plate by capturing its image with a CCD camera and saving the obtained image as a bmp file. Image processing was performed with the help of the specialized ImageDecipher software, following several steps: (i) image reversal in order to obtain densitograms with positive peak; (ii) selecting the area of interest - the spot area; (iii) choosing values for contrast/brightness processing parameters; (iv) choosing the pure color channel (red, blue, green) or neutral-grey channel. The contrast and brightness image processing parameters were modified as follows: the contrast was increased by $10 \%$ (C1), $20 \%$ (C2), 30\% (C3) and the brightness by $20 \%$ (B2), $30 \%$ (B3) and $40 \%$ (B4). Higher percentages of variation were not used as they were leading to information losses or major background changes.

In all cases, peak surface area determined from the digitized chromatograms was used for calibration curve plotting.

\section{ACKNOWLEDGMENTS}

This work has received partial funding from the European Community's Seventh Framework Programme (FP7/2007-2013) under grant agreement $n^{\circ} 245199$. It has been carried out within the PlantLIBRA project (website: www.plantlibra.eu). This report does not necessarily reflect 
INVESTIGATION ON IMAGE PROCESSING PARAMETERS FOR PLATE EVALUATION ...

the Commission views or its future policy on these areas. This paper is also partial supported by the Sectoral Operational Programme Human Resources Development (SOP HRD), financed from the European Social Fund and by the Romanian Government under the project number POSDRU/159/1.5/S/134378 and Bursa Universitatii Transilvania-2016. We hereby acknowledge the structural funds project "R\&D Institute: High-tech products for sustainable development" (ID 123, SMIS 2637, ctr. no. $11 / 2009)$ for providing part of the infrastructure used in this research.

\section{REFERENCES}

1. J. M. Jay, M. J. Loessner, D. A. Golden, "Modern Food Microbiology", 7-th Edition, Springer, New York, 2005.

2. J. I. Pitt, A. D. Hocking, "Fungi and Food spoilage", 2-nd Edition, Springer, New York, 2009.

3. S. Z. Iqbal, M. R. Asi, A. Arino, "Aflatoxins" in "Brenner's Encyclopedia of Genetics", 2-nd Edition, Elsevier, London, 2013.

4. R. C. Gupta, M. A. Lasher, I. R. Miller Mukherjee, A. Srovastava, R. Laal, "Aflatoxins, Ochratoxins, and Citrinin" in "Reproductive and Developmental Toxicology", 2-nd Edition, Elsevier, London, 2017.

5. Commission Regulation (EC) No 1881/2006 of 19 December 2006, "Setting of maximum levels for certain contaminants in foodstuffs", http://eurlex.europa.eu/legal-content/EN/TXT/?uri=CELEX\%3A32006H0576

6. M. Miraglia, B. De Santis, S. Grossi, C. Brera," Mycotoxins" in "Handbook of food analysis", 2-nd Edition, Marcel Dekker, New York, 2004

7. N. W. Turner, S. Subrahmanyam, S. A. Piletsky, Analytica Chimica Acta, 2009, 632, 168.

8. A. Rahmany, S. Jinap, F. Soleimany, Chomprehensive review in food science and food safety, 2009, 8, 202.

9. A. Raiola, G. C. Tenore, L. Manyes, G. Meca, A. Ritieni, Food and Chemical Toxicology, 2015, 84, 169.

10. N. W. Turner, H. Bramhmbhatt, M. Szabo-Vezse, A. Poma, R. Coker, S. A. Piletsky, Analytica Chimica Acta, 2015, 901, 12.

11. L. Wang, Z. Wang, W. Gao, J. Chen, M. Yang, Y. Kuang, L. Huang, S. Chen, Food Chemistry, 2013,138, 1048.

12. Q. Liu, W. Kong, W. Guo, M. Yang, Journal of Chromatography B, 2015, 988, 175.

13. D. Alkadri, J. Rubert, A. Prodi, A. Pisi, J. Manes, C. Soler, Food Chemistry, 2014, 157, 111.

14. L. Wang, Z. Wang, C. Tessini, C. Mardones, D.von Baer, M. Vega, E. Herlitz, R. Saelzer, J. Silva, O. Torres, Analytica Chimica Acta, 2010, 660, 119.

15. A. Prelle, D. Spadaro, A. Garibaldi, M. L. Gullino, Food Control, 2014, 39, 192.

16. N. Arroyo-Manzanares, J. F. Huertas-Perez, L. Gamiz-Gracia, A. M. GarcíaCampana, Talanta, 2013, 115, 61. 
D. CASONI, M. BADEA, I. BROS, S. C. A. COBZAC

17. A. Kamkar, Food Control, 2006, 17, 768.

18. A. A. Fallah, Food Control, 2010, 21, 1478.

19. S. A. Bankole, A. A. Adenusi, O. S. Lawal, O. O. Adesanya, Food Control, 2010, 21, .974.

20. I. Kamika, L. L. Takoy, Food Control, 2011, 22, 1760.

21. M. Mulunda, D.Mike, Food Control, 2014, 39, 92.

22. A. A. Fallah, M. Rahnama, T. Jafari, S. Siavash Saei-Dehkordi, Food Control, 2011, 22, 1653.

23. I. Var, B. Kabak, F. Gok, Food Control, 2007, 18, 59.

24. C. Braicu, C. Puia, E. Bodoki, C. Socaciu, Journal of Food Quality, 2008, 31(1), 108. 